\title{
Medicina alternativa à base de plantas medicinais no tratamento da acne
}

\author{
Alternative herbal medicine for acne treatment \\ Medicina alternativa a base de hierbas para el tratamiento del acné
}

Recebido: 19/01/2021 | Revisado: 25/01/2021 | Aceito: 31/01/2021 | Publicado: 07/02/2021

\author{
Verônica Marin Cubas \\ ORCID: https://orcid.org/0000-0003-0235-5377 \\ Universidade Positivo, Brasil \\ E-mail: veronicacubas2@gmail.com \\ João Luiz Coelho Ribas \\ ORCID: https://orcid.org/0000-0003-0545-5920 \\ Universidade Positivo, Brasil \\ E-mail: jlcribas@yahoo.com.br
}

\begin{abstract}
Resumo
A acne é considerada uma inflamação cutânea crônica a qual acomete jovens e adultos de diferentes faixas etárias. Sua etiologia é multifatorial e desencadeia desde lesões leves até lesões comedogênicas que podem causar cicatrizes por vezes inestéticas. As terapias convencionais apresentam várias limitações, ampliando a busca dos acometidos por terapias alternativas. A medicina alternativa baseia-se na utilização de plantas medicinais e seus derivados, e tem sido usada frequentemente na acne. O objetivo do presente trabalho é analisar como a fitoterapia pode auxiliar no tratamento alternativo da acne. Desta forma, realizou-se uma pesquisa bibliográfica abrangente nas plataformas Scielo, PubMed, Science Direct e Scholar Google com pesquisa entre os anos de 2010 à 2020. Dos 250 artigos selecionados conforme a aplicabilidade do assunto, 30 foram utilizados para esta revisão. $\mathrm{O}$ resultado da pesquisa apresentou uma diversidade de plantas medicinais com potencial significativo no tratamento da acne, dentre elas Camellia sinensis, Orthosiphon stamineus e Rosmarinus officinalis. As plantas com potencial de atuação do tratamento da acne apresentaram compostos bioativos tais como o polifenol Epigalocatequina-3-galato, Estrictinina, Aloemodina, Crisopanol e Aloína, os quais desempenham atividade nas diferentes vias da fisiopatologia da acne, podendo ser uma alternativa de tratamento em relação às terapias convencionais.
\end{abstract}

Palavras-chave: Acne; Propionibacterium acnes; Fitoterapia; Plantas medicinais.

\begin{abstract}
Acne is considered a chronic skin inflammation that affects young people and adults of different age groups. Its etiology is multifactorial and triggers from mild lesions to comedogenic lesions that can cause scars that are sometimes unsightly. Conventional therapies have several limitations, expanding the search for those affected by alternative therapies. Alternative medicine is based on the use of medicinal plants and their derivatives and has been used frequently in acne. The aim of the present work is to analyze how phytotherapy can help in the alternative treatment of acne. Thus, a comprehensive bibliographic search was carried out on the Scielo, PubMed, Science Direct and Scholar Google platforms with research between the years 2010 to 2020. Of the 250 articles selected according to the subject's applicability, 30 were used for this review. The research result showed a diversity of medicinal plants with significant potential in the treatment of acne, among them Camellia sinensis, Orthosiphon stamineus and Rosmarinus officinalis. The plants with potential to act in the treatment of acne presented bioactive compounds such as the polyphenol Epigallocatechin-3-gallate, Strictinina, Aloemodina, Crisopanol and Aloína, which play activity in the different pathophysiology of acne, and can be an alternative treatment for acne in relation to conventional therapies.
\end{abstract}

Keywords: Acne; Propionibacterium acnes; Phytotherapy; Medicinal plants.

\section{Resumen}

El acné se considera una inflamación crónica de la piel que afecta a jóvenes y adultos de diferentes grupos de edad. Su etiología es multifactorial y se desencadena desde lesiones leves hasta lesiones comedogénicas que pueden producir cicatrices en ocasiones antiestéticas. Las terapias convencionales tienen varias limitaciones, ampliando la búsqueda de los afectados por terapias alternativas. La medicina alternativa se basa en el uso de plantas medicinales y sus derivados, y se ha utilizado con frecuencia en el acné. El objetivo del presente trabajo es analizar cómo la fitoterapia puede ayudar en el tratamiento alternativo del acné. Así, se realizó una búsqueda bibliográfica exhaustiva en las plataformas Scielo, PubMed, Science Direct y Scholar Google con investigaciones entre los años 2010 a 2020. De los 250 artículos seleccionados según la aplicabilidad del tema, 30 fueron utilizados para esta revisión. El resultado de la investigación mostró una diversidad de plantas medicinales con un potencial significativo en el tratamiento del acné, 
entre ellas Camellia sinensis, Orthosiphon stamineus y Rosmarinus officinalis. Las plantas con potencial para actuar en el tratamiento del acné presentaron compuestos bioactivos como el polifenol Epigalocatequina-3-galato, Strictinina, Aloemodina, Crisopanol y Aloína, que realizan actividad en las diferentes fisiopatologías del acné, pudiendo ser un tratamiento alternativo para el acné en relación a las terapias convencionales.

Palabras clave: acné; Propionibacterium acnes; Fitoterapia; Plantas medicinales.

\section{Introdução}

A acne é a doença cutânea mais frequente, que atinge 85 a 100\% da população em algum período da vida, sendo a condição mais comum tratada pelos dermatologistas a nível mundial (Melnik, 2018; Silva, Costa, \& Moreira, 2014). A acne interfere diretamente na qualidade de vida dos acometidos que demonstram uma experiência negativa desta condição, com significativo impacto uma vez que pode desencadear cicatrizes, além de influenciar no âmbito psicológico como na baixa autoestima, depressão e ansiedade (Silva et al., 2014).

A acne é uma doença inflamatória crônica da pele caracterizada por acometer o folículo pilossebáceo resultando na inflamação deste folículo (Dessinioti \& Katsambas, 2010). A fisiopatologia da acne compreende os quatro processos principais que ocorrem dentro da unidade pilossebácea, sendo elas a produção sebácea exacerbada, a queratinização atípica do folículo pilossebáceo, e o envolvimento do Cutibacterium acnes com consequente resposta inflamatória (Dreno, Gollnick, Kang, Thiboutot, Bettoli, Torres, \& Leyden 2015; Thiboutot et al., 2009). Segundo Dreno et al. (2015) a inflamação no folículo pilossebáceo estimulada por $C$. acnes é considerada a característica crucial na formação da acne e as terapias abordam principalmente essa via, justificando o extenso uso de agentes antimicrobianos em terapias na acne inflamatória.

O uso de terapias no tratamento da acne é amplo. No que se refere ao de uso tópico estão contemplados majoritariamente os retinóides, peróxido de benzoila, antibióticos e medicamentos complementares e alternativos (CAM) onde ingressam as plantas medicinais (Fox, Csongradi, Aucamp, Plessis, \& Gerber, 2016; Thiboutot, Gollnick, Vincenzo, Dréno, Kang, Leyden, Shalita, Lozada, Berson, Finlay, Goh, Herane, Kaminsky, Kubba, Layton, Miyachi, Perez, Martin, Silva, See, Shear, \& Jr, 2009).

Entre as diversas finalidades terapêuticas em que as misturas advindas de extratos vegetais são utilizadas há séculos na medicina tradicional, destacam-se como moduladores imunológicos naturais, com ação antinflamatórias e antibacteriana (Chahal, Sivamani, Isseroff, \& Dasu, 2013; Fisk, Lev-Tov, \& Sivamani, 2014; Mukherjeea, Maity, Nema, \& Sarkar, 2011; Nichols \& Katiyar, 2010; Saewan \& Jimtaisong, 2015).

As evidências dos efeitos benéficos na acne por intermédio de plantas medicinais já são bem estabelecidas, sugerindo que extratos vegetais e fitoquímicos apresentam capacidade promissora de terapia na acne (Fisk et al., 2014; Yoon, Know, Min, Thiboutot, \& Suh, 2013). No atual cenário de crescente resistência do C. acnes aos antibióticos empregados no tratamento da acne, se faz necessário incrementar terapias alternativas que sejam possíveis aliadas aos tratamentos convencionais (Fox et al., 2016; Ruiz, Hernández, Torres-Tobar, Garzón, Reverend, Ayala, Rueda, \& Díaz, 2019).

Sabendo das potenciais fontes antimicrobianas advindas de diversos produtos naturais, as quais são observadas em muitos medicamentos fitoterápicos que apresentam propriedades antibacterianas, antifúngicas e antivirais concomitantes, a terapia combinada com produtos naturais é uma fonte próspera nesta circunstância (Enioutina, Teng, Fateeva, Brown, Job, Bortnikova, Krepkova, Gubarev, \& Sherwin 2017).

As terapias alternativas com o uso de plantas medicinais são uma promissora opção para sanar os desafios atuais nesse âmbito, podendo ser usadas no tratamento da acne ou como adjuvante nas terapias convencionais (Fisk et al., 2014; Saha, 2012). Entretanto há poucas opções disponíveis de ativos fitoterápicos em formulações destinadas ao tratamento na acne. Desta forma, o presente trabalho tem como objetivo analisar como a fitoterapia pode auxiliar no tratamento alternativo da acne. 


\section{Metodologia}

O presente estudo utilizou como fonte de pesquisa, bases de dados Scielo, PubMed, Science Direct e Scholar Google, utilizando os descritores acne e plantas medicinais, Propionibacterium acnes, Cutibacterium acnes, medicina complementar alternativa e acne, selecionando artigos de 2010 a 2020. Após leitura do título e abstract foram inclusos 250 artigos com base na abrangência específica do tema. Destes, 30 foram selecionados para composição deste trabalho e abordaram de forma relevante a utilização de plantas medicinais na acne ou nas vias associadas ao seu desenvolvimento.

\section{Resultados e Discussão}

A classificação da gravidade da acne não apresenta um consenso universal. De acordo com Ramli, Malik, Hani e Jamil (2012) mais de 25 classificações acerca da gravidade da acne foram apresentadas em literatura, entretanto não há estabelecido um padrão preconizado a se seguir deste tópico. Os sistemas de classificação baseiam-se em contagens de lesões ou em padrões fotográficos. Os sistemas de classificação que consideram as lesões avaliam o número de comedões abertos e fechados, pápulas, pústulas e nódulos. O método fotográfico compara fotos dos pacientes acometidos com padrões estabelecidos fotográficos (Ramli et al., 2012). Segundo Dreno et al. (2011) a gravidade da acne está associada com as características das lesões, como o tipo e a distribuição das mesmas. Uma das primeiras classificações introduzidas quanto à gravidade da acne já se baseava em fatores como tipo, número e predomínio das lesões, expondo a continuação destes parâmetros até hoje levados como critérios de avaliação (Ramli et al., 2012).

A Food and Drug Administration (FDA) recomenda o uso da classificação da avaliação global do investigador (IGA) na gravidade da acne. A escala pode ser categorizada por números de 0 a 4 , onde se infere que cada qual apresente um conjunto de características específicas na gravidade da acne. Considerando a quantidade e o tipo das lesões presentes na face levando em consideração também outras regiões do acometido, devendo ser inclusa a contagem das lesões presentes no nariz. A escala de IGA é dividida em grau zero, quando a pele está isenta de lesões inflamatórias e não inflamatórias. No grau 1 a pele apresenta raras lesões inflamatórias, com não mais que uma lesão inflamatória pequena. O grau 2 se sobressai ao grau 1, com gravidade leve, onde há algumas lesões não inflamatórias com não mais que poucas lesões inflamatórias abrangendo apenas pápulas e pústulas, isentando as lesões nodulares. O grau 3 considerado com moderada severidade, compreende muitas lesões não inflamatórias, podendo ter algumas lesões inflamatórias, mas não mais que uma pequena lesão nodular. Por fim o grau 4, grave, podendo ter muitas lesões não inflamatórias, algumas lesões inflamatórias, mas não mais que algumas lesões nodulares. A acne nódulo cística a qual apresenta lesões superiores às descritas no grau quatro, devem ser descritas na avaliação de segurança, para uma comunicação dos investigadores sobre as condutas de tratamento (Food and Drug Administration [FDA], 2018).

O Quadro 1 sugere os parâmetros avaliativos quanto ao tipo da lesão. O desenvolvimento de uma padronização da gravidade da acne se baseando na escala IGA a qual é usada amplamente em ensaios clínicos, pode ser uma ferramenta útil na prática para abordar e compreender resultados de tratamentos (Dreno et al., 2011). 
Quadro 1. Tipos de lesões e suas respectivas características.

\begin{tabular}{|c|c|c|c|c|}
\hline Lesão & Tamanho & Cor & Pus & Implicações \\
\hline Comedo fechado & Minúsculo & Esbranquiçado & Isento & $\begin{array}{l}\text { Sem dor, não } \\
\text { inflamatório }\end{array}$ \\
\hline Comedo aberto & Minúsculo & Preto ou marrom & Isento & $\begin{array}{l}\text { Sem dor, não } \\
\text { inflamatório }\end{array}$ \\
\hline Pápula & $<5$ mm de diâmetro & Rosado & Isento & $\begin{array}{l}\text { Doloroso, apresenta } \\
\text { inflamaçã̃o }\end{array}$ \\
\hline Pústula & $<5$ mm de diâmetro & $\begin{array}{c}\text { Avermelhado na base com } \\
\text { um centro amarelado ou } \\
\text { esbranquiçado }\end{array}$ & Presente & $\begin{array}{l}\text { Doloroso, apresenta } \\
\text { inflamação }\end{array}$ \\
\hline Nódulo & 5-10 mm de diâmetro & Rosado e avermelho & Isento & $\begin{array}{l}\text { Doloroso, apresenta } \\
\text { inflamação }\end{array}$ \\
\hline Cisto & Diametro maior que $5 \mathrm{~mm}$ & Avermelhado & $\begin{array}{l}\text { Isento de pus, contém } \\
\text { líquido no interior }\end{array}$ & $\begin{array}{l}\text { Doloroso, apresenta } \\
\text { inflamação }\end{array}$ \\
\hline
\end{tabular}

Fonte: Adaptado de Ramli et al. (2012).

\subsection{Inflamação e mediadores pró-inflamatórios}

O processo inflamatório está associado principalmente ao C. acnes, sendo o principal ocupante da unidade pilossebácea responsável por 90\% da microbiota em locais sebáceos (Grice, Kong, Conlan, Deming, Davis, Young, Bouffard, Blakesley, Murray, Green, Turner, \& Segre, 2009). Além do C. acnes, o Staphylococcus epidermidis também está presente no folículo e ambas as bactérias coexistem na superfície da pele e dentro do folículo (O’neill \& Gallo, 2018). Embora o papel do C. acnes no desenvolvimento da acne seja mais conhecido, este microrganismo é considerado um comensal benéfico para a pele. Especula-se que outras bactérias em menor proporção contribuam indiretamente para este processo inflamatório, como o Staphylococcus aureus que é considerada uma bactéria patogênica para a pele podendo contribuir para este processo (Lee, Byun, \& Kim, 2019). Em estudo realizado por Pathak, Kasama, Kumar e Gautam (2013) observaram que S. epidermidis foi mais prevalente em pacientes com acne do que no grupo controle, neste estudo o qual utilizou modelos de explante, relatam que esta bactéria previne a acne por exercer atividade antimicrobiana, enquanto $C$. acnes aumentam a progressão da doença. Corroborando com Pathak et al. (2013) e Lee, Byun e Kim (2019) citam que alguns estudos sugerem que S. epidermidis que é um Staphylococcus comensal na pele humana, tem a capacidade de interagir com C. acnes e inibir o crescimento do mesmo. Sugerindo que S. epidermidis pode desempenhar um papel na prevenção da acne, mas essa hipótese precisa ser mais bem avaliada.

Descrito por Lomholt e Kilian (2010) o C. acnes está intimamente envolvido no processo inflamatório da acne, a bactéria não se restringe apenas induzindo a liberação de citocinas pró-inflamatórias, também estimula a liberação de enzimas como as lipases, proteinases e hialuronidades as quais causam agravos ao folículo pilossebáceo, além de ativar vias do sistema imune inato como a via dos receptores Toll-like (TLRs) (Jasson, Nagy, Knol, Zuliani, Khammari, \& Dréno 2013; Kistowska, Gehrke, Jankovic, Kerl, Fettelschoss, Feldmeyer, Fenini, Kolios, Navarini, Ganceviciene, Schauber, Contassot, \& Francês, 2014; Bhambri, Rosso, \& Bhambri, 2009).

Através de pesquisas elucidou-se a capacidade imunomoduladora dos extratos vegetais, dentre eles como moduladores dos receptores Toll-like (TLRs), já descritos o Ginkgo biloba L., Chrysanthemum coronarium L. e Arnica montana L. Os TLRs são receptores transmembrana que reconhecem padrões conservados, e estão envolvidos precocemente na resposta imune natural do organismo (Chahal el al., 2013). Os TLRs podem iniciar uma reposta imune decorrente da interação com PAMPs (Padrões moleculares associados a patógenos), como os componentes da parede celular bacteriana ou 
material genético, em resposta a esta interação há o estímulo dos TLRs proporcionando a ativação de diversas vias intracelulares, ocasionando a liberação de citocinas pró-inflamatórias e imunomoduladoras (Wolff, Johnson, Saavedra, \& Roh, 2019; Mcinturff \& Kim, 2005; Mcinturff, Modlin, \& Kim, 2005). De acordo com Kim (2005) o C. acnes ativa TLR-2 e TLR4. Também há evidências sugerindo os possíveis papéis patogênicos do S. aureus na inflamação presente na acne, pelo estímulo do receptor Toll-like 2 (Dhillon \& Varshney, 2013; Totté, Feltz, Bode, Belkum, Zuuren, \& Pasmans,, 2016).

Em estudo realizado por Kim et al. (2002) revelaram que de maneira semelhante, há o aumento da expressão de TLR2 por células conforme o aumento no grau de severidade da acne. As citocinas pró-inflamatórias também apareceram em proporções maiores conforme a interação entre TLR-2 e C. acnes (Feldman et al., 2011). Segundo Montagner e Costa (2010) mediadores inflamatórios como a interleucina-1 (IL-1) que está associada com a comedogênese na acne, são liberados pelos queratinócitos infundibulares em resposta a uma perturbação decorrente de mudanças na composição da secreção sebácea. Segundo Zouboulis, Jourdan e Picardo (2014) a ação do C. acnes na iniciação da reação inflamatória deve-se ao estímulo da secreção da IL-18, Fator de necrose Tumoral (TNF $\alpha$ ), IL-8 e IL-12 pelas células monocíticas. A IL-8 é um potente mediador inflamatório, pois é fator quimiotático para neutrófilos e células $\mathrm{T}$ além de auxiliar na arquitetura da resposta inflamatória nas lesões da acne. No estudo realizado por Kistowska et al. (2014) foi observado da mesma maneira uma correlação do C. acnes na contribuição no desenvolvimento das lesões inflamatórias por estimular a secreção de IL-18, TNF $\alpha$, IL- 8 e IL-12, além de demonstrar o estímulo também da IL-6 e IL-1 $\beta$. Nesta investigação foi constatado que a IL-1 $\beta$ está presente em grande quantidade nas lesões da acne, e que a exposição do C. acnes nas células avaliadas foi determinante para o estímulo da produção da mesma. Os dados sugerem que o direcionamento da produção e secreção de IL-1 $\beta$ seria uma potente opção para o tratamento da acne.

Uma opção de tratamento para acne que envolve marcadores inflamatórios foi sugerida por Sand e Thomsen (2013), onde descreveram a correlação da reação inflamatória induzia por $C$. acnes em queratinócitos e o adiantamento da produção de TNF $\alpha$. Mencionam a melhora significativa em estudos que procederam tratamento em pacientes com acne grave e o uso de inibidores de TNF $\alpha$. Os dados referentes aos marcadores inflamatórios indicam que terapias voltadas para este direcionamento, podem ser opções promissoras no tratamento da acne.

\subsection{Tratamentos convencionais}

As substâncias utilizadas no tratamento da acne são definidas conforme a gravidade do caso. Nos casos leves e moderados frequentemente são utilizados agentes tópicos como retinóides e fármacos antibacterianos. Nos casos mais graves de acne os medicamentos comumente empregados são os antibióticos sistêmicos, terapias hormonais e o uso da Isotretinoína oral (Brasil, 2015). Os antibióticos tópicos que são utilizados nos casos de acne leve a moderada, atuam sobre a acne inflamatória pela sua ação antimicrobiana sobre o $C$. acnes e são utilizados em associação com outras categorias de ativos, como associados com os retinóides tópicos e o peróxido de benzoíla em maior proporção (Kim \& Ochsendorf, 2016; Leyden, 2003; Williams, Dellavalle, \& Garner, 2012). Todos os antibióticos de uso tópico apresentam potencial irritação local, entretanto menos significativos comparados aos antibióticos sistêmicos (Leyden, 2003). Os antibióticos de uso oral são utilizados no tratamento da acne grave, quando a terapia tópica não apresenta resultados satisfatórios (Williams et al., 2012).

$\mathrm{O}$ tratamento com as terapias convencionais de uso tópico e oral podem apresentar efeitos colaterais significativos, como a irritação cutânea, alterações gastrintestinais, infecções, xerose, mialgias, além do desenvolvimento da resistência bacteriana aos medicamentos (Canavan, Chen, \& Elewski, 2016; Fisk et al., 2014; Thiboutot, 2011). São evidentes os efeitos adversos que as terapias tradicionais utilizadas para acne desencadeiam, fato este visto também em anormalidades laboratoriais. Quando há o uso da Isotretinoína, fármaco utilizado nos casos mais graves da acne, o risco relacionado à teratogenicidade é significativo. Desta maneira as terapias convencionais causam por muitas vezes a intolerância do paciente, 
fazendo com que interrompam o tratamento (Canavan et al., 2016; Mansu, Coyle, Wang, May, Zhang, \& Xue, 2018; Saha, 2012).

A terapia com antibióticos tópicos e sistêmicos na acne em longo prazo propicia o desenvolvimento de cepas resistentes de C. acnes (Castillo, Nanda, \& Keri, 2019). Segundo Sadhasivam, Sinha, Saini, Kaur, Gupta, Sengupta, Ghosh e Sardana, (2016) a resistência do $C$. acnes aos antibióticos está entre os principais fatores que influenciam na falha no tratamento da acne. Com esta atual condição, é aconselhada a maximização de terapias que priorizem a redução da utilização de antibióticos, considerando que a crescente resistência a estes agentes representa uma preocupação de saúde pública para o futuro (Canavan et al., 2016).

De acordo com Fox et al. (2016) o público em geral tem demonstrado o interesse gradual por métodos alternativos no tratamento da acne, buscam por produtos mais naturais os quais consideram mais seguros. As terapias botânicas apresentam composição ampla e variada o que possibilita sua ação frente vários mecanismos de ação envolvidos nesta patogenia (Fisk et al., 2014). Segundo Fisk, Lev-Tov e Sivamani (2014) e Nasri, Bahmani, Shahinfard, Nafchi, Saberianpour, \& Kopaei, (2015) o uso de produtos fitoquímicos em produtos dermatológicos tem crescido significativamente, devido as suas ações terapêuticas e por demonstrar ao longo da história poucos efeitos colaterais. Com a elucidação das atividades antiinflamatórias e antimicrobianas evidenciadas com extratos vegetais estes agentes são uma fonte promissora para o desenvolvimento de novos medicamentos (Nasri et al., 2015).

\subsection{Medicamentos complementares e alternativos}

A utilização de plantas medicinais como tratamento e cura de doenças é uma realidade advinda dos povos antigos e que se estende na ciência moderna (Buffon, Lima, Galarda, \& Cogo, 2001). Os produtos naturais derivados de plantas destinados à pele são incorporados em formulações cosméticas para tratamentos de antienvelhecimento, cicatrização, dermatites e acne (Leal \& Lara, 2019). Essas funções devem-se as propriedades terapêuticas que os ativos advindos de plantas medicinais apresentam, como imunomoduladores e como potentes agentes no controle da inflamação (Chahal et al., 2013). Segundo Matsuchita e Matsuchita (2014) inúmeros fármacos têm sido empregados para o tratamento da acne, entretanto as pesquisas são direcionadas para terapias alternativas com compostos naturais, pois pesquisas que investigam a ação de extratos de plantas já demonstraram em muitos resultados efeitos positivos no tratamento da acne.

\subsubsection{Modulação da secreção sebácea}

No estudo realizado por Yoon et al. (2013) foram investigados os efeitos do principal polifenol Epigalocatequina-3galato (EGCG) do chá verde na modulação dos alvos moleculares associados na patogênese da acne. Os resultados mostraram a capacidade do EGCG em diminuir a inflamação, a produção sebácea além de reduzir a viabilidade do $C$. acnes, evidenciando que o polifenol EGCG do chá verde apresenta-se como um potente agente terapêutico para a acne. De maneira semelhante Mahmood, Akhtar, Khan, Khan e Saeed (2010) avaliaram os efeitos de uma formulação de uso tópico contendo extrato de chá verde Camellia sinensis L., a qual foi utilizada para delinear os potenciais efeitos do extrato sobre a produção sebácea da pele em voluntários humanos sadios. Com a metodologia ideal para análise das medidas da produção sebácea, utilizou-se na formulação 3\% de extrato etanólico de chá verde. Os resultados demonstraram a sebosupressão decorrente da aplicação tópica do extrato de chá verde, efeito também observado em modelos animais na aplicação tópica de EGCG (Liao, 2001).

O mecanismo envolvido na sebossupressão desencadeado pelo uso tópico do chá verde de acordo com Liao (2001) e Mahmood, Akhtar e Moldavo (2013) é devido a inibição das $5 \alpha$ redutase, sugerindo que esta atividade seja provinda do polifenol EGCG. Os mecanismos descritos por Yoon et al. (2013) estão associados à via de sinalização AMPK (proteína cinase ativada por AMP) e SREBPs (proteínas de ligação ao elemento regulador de esterol) também desencadeados por EGCG. 
De acordo com Melnik e Schmitz (2013) a SREBP- 1c regula positivamente a estearoil-CoA e a A6-dessaturase, aumentando a proporção de ácidos graxos monoinsaturados nos triglicerídeos da secreção sebácea. Foi postulado por Porstmann, Santos, Lewis, Griffiths e Schulze (2009) que o principal fator de transcrição da biossíntese de lipídeos é a SREBP, sendo dependente da ativação do alvo mecanístico do complexo 1 da rapamicina (mTORC1), que por sua vez controla o acesso de SREBP-1 na região promotora nos respectivos genes no núcleo. A correlação do estímulo de mTORC1 com consequente expressão de SREBP-1c resulta na produção sebácea, também foi evidenciado por Melnik (2015). Em seu estudo foi investigado o desempenho da dieta ocidental nas vias de sinalização que corroboram para o desenvolvimento da acne, dentre eles o principal regulador da lipogênese envolvendo o alvo mTORC1.

Na pele de indivíduos com acne foi exposto por Melnik e Zouboulis (2013) que há um aumento de fosfoinositida 3quinase-Akt-mamífero do complexo 1 da rapamicina (PI3K-Akt-mTORC1), considerado por Melnik (2015) uma cascata com papel fundamental na acne quando esta encontra-se com maior atividade. Inúmeras vias convergentes dependentes de mTORC1 aumentam a ativação de SREBP-1c (Quinn \& Birnbaum, 2012). Sendo assim os inibidores naturais do mTORC1, apoiam a hipótese considerando sua atividade, de possíveis agentes nas terapias para a acne. A Epigalocatequina-3-galato foi considera por Melnik e Schmitz (2013) um inibidor natural de mTORC1.

Segundo Yoon et al. (2013) a Isotretinoína e a terapia hormonal eram as únicas terapias consideradas eficientes na redução da produção sebácea. Com os resultados de seu estudo, de Mahmood et al. (2010) e dos expostos por Mahmood et al. (2013) os quais apresentaram a sebosupressão decorrente da formulação de uso tópico do extrato de chá verde, sugere-se o uso do ECGC como um possível ativo no tratamento em desordens de pele que envolvem a produção sebácea, como a acne.

A investigação de plantas medicinais com a capacidade de modular a secreção sebácea foi também investigada por Vogelgesang, Malak, Reymermier, Altobelli e Saget (2011) os quais analisaram esta atividade utilizando $2 \%$ do extrato da folha de Orthosiphon stamineus Benth., conhecida popularmente como "chá java" ou "bigode de gato". O resultado deste estudo demonstrou uma potente redução da expressão do RNAm da $5 \alpha$ redutase tipo 1 em queratinócitos epidérmicos humanos normais in vitro, e confirmados in vivo por metodologias apropriadas, além de apresentar a redução do esqualeno, que é um dos principais componentes da secreção sebácea. A modulação da secreção sebácea está intimamente relacionada com o desenvolvimento da acne, sugerindo que ativos que desempenham atividade sebossupressora sejam candidatos para o desenvolvimento de cosméticos anti acne. Estes ativos podem ser advindos de plantas medicinais devido a sua composição exacerbada de componentes potencialmente ativos (Fisk et al., 2014).

\subsubsection{Atividade antibacteriana}

A elucidação da capacidade antimicrobiana a partir de diversas plantas medicinais contra bactérias já foram apresentadas em múltiplos resultados de pesquisas, dentre as bactérias avaliadas está o Cutibacterium acnes (Jeong \& Kim, 2017). Dentre os polifenóis, os flavonóis e taninos se sobressaem, referentes à sua atividade antimicrobiana comparada aos outros polifenóis. Esta atividade é capaz de suprimir bactérias além de fatores de virulência, como dificultar a formação de biofilme e neutralizar toxinas bacterianas (Daglia, 2012). Esta atividade possivelmente está atrelada aos achados referentes aos polifenóis, que são produzidos pelas plantas como uma estratégia de defesa contra agentes externos, dentre eles as bactérias (Eumkeba, Sakdara, \& Siriwonga, 2010).

Há evidências descritas sobre a ação sinérgica dos flavonoides com outros antibióticos contra microrganismos multirresistente (Daglia, 2012). Em estudo realizado por Hsieh, Xu, Lin, Li, Chen, Kuo, Chen, \& Tzen (2016) que envolveu como fonte de pesquisa o chá Pu'er, o chá é produzido a partir de folhas jovens de árvores silvestres de Camellia sinensis var. Assamica, através um processo denominado pós fermentação. Este chá apresentou possuir compostos fenólicos, sendo o principal a Estrictinina (Maeda-Yamamoto, Nagai, Asai, Tachibana, Miyase, San, Moriwaki, Horie, \& Kohata,, 2004). 
Na pesquisa realizada por Hsieh et al. (2016) avaliaram a atividade antibacteriana da Estrictinina e de dez antibióticos comumente utilizados no tratamento de infecções bacterianas, sobre a capacidade de inibir o crescimento de $C$. acnes e $S$. epidermidis. A associação da atividade antibacteriana da Estrictinina contra $C$. acnes com os antibióticos Gentamicina e Cefmetazol exerceram um efeito sinérgico, enquanto os outros oito antibióticos sendo estes a Eritromicina, Neomicina, Flomoxef, Cefepime, Ceftazidina, Tetraciclina, Piperacilina e Amoxicilina exibiram um efeito aditivo. A atividade antibacteriana combinada da Estrictinina com os seis antibióticos Eritromicina, Gentamicina, Neomicina, Flomoxef, Cefepime e Cefmetazol contra S. epidermidis exibiram um efeito aditivo, enquanto a Ceftazidina, Tetraciclina, Piperacilina e Amoxicilina foram incapazes de inibir S. epidermidis (Hsieh et al., 2016). A Estrictinina isolada do chá apresentou atividade antibacteriana, e um efeito aditivo ou sinérgico quando associada aos antibióticos testados, sendo assim a associação da Estrictinina com antibióticos comumente utilizados na terapêutica mostra-se como uma opção de substituto natural moderado para antibióticos (Hsieh et al., 2016).

Dentre os polifenóis presentes no chá verde o EGCG é o composto bioativo em maior abundância segundo Lamarão e Fialho (2009). No estudo desenvolvido por Yoon et al. (2013) a atividade de EGCG sobre o C. acnes foi investigada com o intuito de elucidar sua atividade antimicrobiana, considerando estudos anteriores onde EGCG apresentou esta atividade contra diversos microrganismos. O EGCG no presente estudo mostrou redução significativa na formação de colônias de $C$. acnes de maneira dose dependente de EGCG. A atividade antibacteriana do extrato do chá verde também foram descritas por Li et al. (2015), onde avaliaram a atividade do extrato frente as bactérias envolvidas na patogênese da acne. As bactérias testadas foram Cutibacterium acnes, Propionibacterium granulosum, Staphylococcus aureus e Staphylococcus epidermidis, com resultados satisfatórios, apontando a atividade antibacteriana dos extratos sobre todas as bactérias avaliadas.

A combinação de antibióticos com os polifenóis encontrados em plantas responsáveis por esta ação bactericida de amplo espectro sugerem uma opção de tratamento efetiva como antimicrobianos contra o $C$. acnes, e consequente aliado na redução da colonização e desenvolvimento da acne (Eumkeba et al., 2010; Yonn et al., 2013).

Em estudo realizado por Vora, Srivastava e Modi (2018) com os extratos metanólicos das plantas Rosmarinus officinalis L., Pelargonium asperum Ehrh., Ocimum tenuiflorum L., Acacia nilotica L., Azadirachta indica A. Juss., Matricaria chamomilla L. e Calendula officinalis L., investigou-se a atividade antibacteriana contra alguns tipos de bactérias, dentre elas as presentes na acne como o Staphylococcus aureus e Cutibacterium acnes. O método utilizado para a avaliação da atividade antibacteriana foi o de disco difusão em ágar e seus resultados apontaram diferenças nas faixas da zona de inibição. Em suma todos os fitoterápicos testados apresentaram atividade contra $C$. acnes com faixas de zona de inibição, entretanto com valores significativos os extratos vegetais de $R$. officinalis, M. chamomilla e A. nilotica que apresentaram zonas de inibição com diâmetro de $8 \mathrm{~mm}, 6 \mathrm{~mm}$ e $4 \mathrm{~mm}$ respectivamente. O extrato de $R$. officinalis foi o único extrato que apresentou inibição contra S. aureus. A concentração inibitória mínima (CIM) foi testada dos três extratos, $R$. officinalis, M. chamomilla e A. Nilotica, no resultado os valores da CIM de $R$. officinalis aproximou - se dos valores de referência padrão da isotretinoína contra S. aureus. $\mathrm{O}$ extrato de $M$. chamomilla e de $R$. officinalis apresentaram uma CIM significativa contra $C$. acnes comparada com o medicamento anti acne padrão (Isotretinoína) (Vora, Srivastava, \& Modi, 2018). Além do extrato o óleo essencial da $R$. Officinalis também apresentou atividade antibacteriana contra C. acnes em pesquisa realizada por Silva et al. (2011). O resultado do estudo realizado por Vora et al. (2018) sugeriu que os três extratos poderiam ser utilizados como formulações naturais para o tratamento da acne, sobressaindo a atividade de $R$. officinalis nos resultados do presente estudo. Em pesquisa procedida por Issabeagloo, Kermanizadeh, Taghizadieh e Forughi (2012) o óleo essencial de Rosmarinus officinalis foi avaliado frente à ação antibacteriana contra S. aureus. Os resultados corroboram com os de Vora et al. (2018), apresentando efeito inibitório contra S. aureus, e evidencia esta atividade de forma dose dependente. Almela, Sánchez-Muñoz, FernándezLópez, Roca e Rabe (2006) descreveram que no extrato de Rosmariunus oficinalis há grupos fenólicos, possivelmente os 
responsáveis pela ação antibacteriana do extrato.

A atividade antibacteriana envolvendo óleo essencial também foi abordada por Hou, Bonku, Zhai, Zeng, Hou, Yang, \& Quan (2019). Neste estudo foi investigada a capacidade do óleo essencial extraído da casca de Citrus reticulata Blanco L. em apresentar efeitos antibacterianos sobre alguns microrganismos. A C. reticulata é uma variedade de laranja comum com maior produção na China, a composição do óleo essencial $(\mathrm{OE})$ da casca da $C$. reticulata é principalmente baseada em terpenos, onde integra especialmente o d-limonemo já apresentado em estudos anteriores. A atividade antimicrobiana do OE da C. reticulata e do seu principal constituinte o d-limonemo foram testadas simultaneamente contra o C. acnes, S. aureus, B. subtilis e E. coli. Mais além foi realizada a comparação da eficiência antimicrobiana do $\mathrm{OE}$ da C. reticulata contra C. acnes e de antibióticos tradicionais como a Clindamicina, Eritromicina e Tetraciclina. Os resultados apresentaram notável atividade antibacteriana do $\mathrm{OE}$ da $C$. reticulata e do d-limonemo frente aos microrganismos testados. O resultado referente à comparação dos antibióticos e do $\mathrm{OE}$ cítrico contra C. acnes, apresentou uma maior ação antibacteriana do $\mathrm{OE}$ cítrico comparado com os antibióticos avaliados. A pesquisa mostrou atividade antibacteriana do OE contra $C$. acnes superior a Eritrocimina, Tetraciclina e Clindamicina respectivamente. Os dados sugerem que o óleo essencial da casca de C. reticulata pode ser aplicado como uma opção de ativo antibacteriano contra $C$. acnes, auxiliando no tratamento da acne (Hou et al., 2019).

A atividade antibacteriana do extrato da folha de Myrtus communis L. veiculada a um creme foi testada por Pecastaings, Roque, Nocera, Mengeaud, Khammari \& Dréno, (2018) sob a colonização de C. acnes. O estudo que utilizou como base um creme contendo o extrato de $M$. communis demonstrou ter atividade antibacteriana isoladamente ou combinada com antibióticos sobre o biofilme de C. acnes. Mais além, o creme com o extrato foi capaz de potencializar a atividade bactericida dos antibióticos frente ao $C$. acnes, e demonstrou in vivo uma redução significativa de estirpes de Cutibacterium acnes resistentes a Eritrocimina, levando a uma redução das lesões da acne.

$\mathrm{O}$ avanço da produção e disponibilidade dos antibióticos desenvolveu a rápida propagação da resistência bacteriana em grande parte dos antibióticos disponíveis (Michael, Dominey-howes, \& Labbate, 2014). Na acne especificamente o uso de antibióticos no tratamento desencadeou mudanças nos padrões de resistência do C. acnes (Leyden, 2012). Desta maneira devese considerar cuidadosamente o uso dessa classe de medicamentos no tratamento da acne (Canavan et al., 2016). Com base nesses estudos, fica evidente a capacidade antibacteriana dos fitoterápicos frente a diversos tipos e bactérias ressaltando a do $C$. acnes. Esta atividade revela que alguns compostos ativos derivados de plantas medicinais até se sobressaem no que se refere à capacidade antimicrobiana, comparada a alguns antibióticos comumente empregados na terapia da acne. Infere-se que o uso de plantas medicinais como agentes antimicrobianos são potentes ativos para desempenhar esta função bactericida.

\subsubsection{Modulação na inflamação}

Os extratos dos grãos de frutos crus de Mangifera indica L. foram testados por Poomanee, Chaiyana, Mueller, Viernstein, Khunkitti e Leelapornpisid (2018) como uma possível terapia anti acne, onde foi investigada a sua atividade antibacteriana contra Cutibacterium acnes, Staphylococcus aureus e Staphylococcus epidermidis, bactérias envolvidas na acne. Foi avaliado o efeito sobre a secreção de IL-8 e IL- 6 induzidas por lipopolissacarídeo, o qual foi utilizado preliminarmente para o estímulo da produção das citocinas em linhagem celular adequada. Os extratos foram eficazes contra as bactérias aeróbias e anaeróbias, a fração etanólica exibiu um efeito antibacteriano significativamente maior contra $C$. acnes comparado com as outras frações dos extratos. Neste estudo foi sugerido o mecanismo de ação dos extratos de $M$. indica contra $C$. acnes, supondo que seja devido ao alto teor de compostos polifenólicos que promovem danos à membrana celular do C. acnes com consequente liberação de substâncias citoplasmáticas (Daglia, 2012). Os polifenóis apresentam toxicidade sobre vários microrganismos de plantas já elucidados (Carson, Mee, \& Riley, 2002). 
Os resultados foram satisfatórios com relação ao efeito inibitório sobre o C. acnes, S. aureus e S. epidermidis, revelando atividades antibacterianas relevantes (Poomanee et al., 2018). A atividade avaliada na secreção das IL-6 e IL-8 demonstraram que os extratos exerceram efeito inibitório significativo sobre a secreção de IL-8, e não apresentaram este efeito sobre a IL-6, revelando a atividade antinflamatória dos extratos dos grãos de Mangifera indica sobre a IL- 8 que está presente na inflamação desencadeada pelo C. acnes (Poomanee et al., 2018).

Em pesquisa realizada por Tsai et al. (2016) que utilizou o extrato da raiz de Scutellariae radix purificado do qual foi isolado sete flavonas sendo estas a (5,7-dihidroxi-6-metoxiflavona, 5,7-dihidroxi-8-metoxiflavona, 5-hidroxi-7,8dimetoxiflavona, 5,6'-di-hidroxi-6,7,8,2'-tetrametoxiflavona, 5,7,4'-tri-hidroxi-8- metoxiflavona, 5,2',6'-trihidroxi-7,8dimetoxiflavona e 5,7,2',5'-tetrahidroxi-8,6'-dimetoxiflavona) com o objetivo de verificar o efeito supressor na inflamação induzida por $C$. acnes. A indução da inflamação foi realizada por $C$. acnes preliminarmente em células monocíticas humanas com posterior produção de IL-8 e IL- $\beta$, as sete flavonas isoladas da raiz de $S$. radix reduziram significativamente os níveis de IL-8 e IL-1 $\beta$ de maneira dose dependente. Outras moléculas pró-inflamatórias como a IL-6 e TNF- $\alpha$ foram avaliadas, sendo induzidas por injeção intradérmica em orelhas de camundongos por $C$. acnes, com injeção concomitante de cada uma das flavonas. Os resultados mostraram a supressão do edema induzido por $C$. acnes e observou que as sete flavonas inibiram significativamente a produção de IL-6 e TNF- $\alpha$ em orelhas de camundongos tratados com C. acnes. O resultado obtido do extrato da raiz de Scutellariae radix apresentou inibição das interleucinas IL-8, IL-1 $\beta$, IL-6 e do TNF- $\alpha$ que são mediadores pró-inflamatórios induzidos por $C$. acnes. Este estudo demonstrou que as sete flavonas testadas apresentam potencial uso terapêutico contra a inflamação cutânea presente na acne (Tsai et al., 2016).

Alguns marcadores moleculares como IL-1 $\alpha$, IL-1 $\beta$, TNF- $\alpha$ e IL-8 estão aumentados na inflamação induzida por $C$. acnes segundo Yoon et al. (2013). Em seus experimentos onde testou o ECGC, um polifenol presente no chá verde, apresentou resultados significativos na redução dos níveis de RNAm da IL-1 $\alpha$, IL-1 $\beta$, IL-8 e TNF- $\alpha$ nos sebócitos nos quais foram submetidos à pesquisa. A redução da resposta inflamatória induzida por C. acnes em modelo in vitro segundo o autor é através da inibição das vias de sinalização NF-kB e AP-1. A pesquisa realizada por Choo, Kundap, Kumari, Hue, Othman \& Shaikh, (2018) avaliou o extrato etanólico das folhas de Orthosiphon stamineus acerca da sua capacidade antinflamatória, que apresentou em seus resultados a regulação negativa do TNF- $\alpha$, sendo este uma citocina envolvida na inflamação. Yam, Lim, Salman, Ameer, Ang, Rosidah, Abdulkarim, Abdullah, Basir, Sadikun \& Asmawi, (2010) citaram em seu estudo os componentes das folhas de $O$. Stamineus sugerindo as responsáveis pelo efeito antinflamatório, a classe contemplada foi a das flavonas, que possivelmente funcionam inibindo a via do óxido nítrico.

A ação antinflamatória do extrato de Aloe ferox Mill. foi avaliada por Jeong e Kim (2017), em sua pesquisa o extrato da planta Aloe ferox foi preparado com diferentes solventes em diferentes proporções. Para a investigação do possível efeito antinflamatório do extrato sobre o $C$. acnes, células THP-1 foram cultivadas com $C$. acnes o qual induziu a produção de citocinas pró-inflamatórias como TNF- $\alpha$, IL-1 $\beta$, IL-6 e IL-8. Os resultados mostraram que a presença de todos os extratos testados de A. ferox no tratamento das células THP-1 induzidas por C. acnes apresentaram uma redução das citocinas próinflamatórias TNF- $\alpha$, IL-1 $\beta$, IL-6 e IL-8 de maneira dependente da concentração dos extratos. Assim como outros extratos derivados de plantas, o extrato de Aloe ferox apresenta capacidade antinflamatória, decorrente dos efeitos desencadeados pelo C. acnes, sendo um possível agente terapêutico voltando para a inflamação no contexto da acne (Jeong \& Kim, 2017).

Devido a esses tratamentos envolvendo medicina alternativa complementar, que utiliza de produtos mais naturais e apresentarem em geral menos efeitos colaterais, os pacientes têm mostrado maior interesse e adesão a terapias com plantas medicinais e seus derivados como alternativas voltadas para o tratamento da acne (Fox et al., 2016; Yoon et al., 2013). De acordo com Han, Blencke, Cheng e Li (2018) a conduta para o controle efetivo no tratamento da acne procede em impedir a colonização bacteriana e a inflamação no folículo pilossebáceo. Desta maneira o rastreamento de substâncias com potencial 
ação antinflamatória e antibacteriana são a conduta apropriada para a descoberta de novas substâncias testes. Neste contexto, há uma constante tentativa de rastrear e desenvolver outras abordagens que reforcem as atividades das terapias comumente utilizadas ou inovadoras no contexto na terapia na acne (Upadhyay, Upadhyaya, Kollanoor-Johny, \& Venkitanarayanan, 2014).

No Quadro 2, pode-se observar um resumo das principais plantas medicinais e princípios ativos publicados e inclusos neste trabalho correlacionando com sua atividade biológica e mecanismo de ação.

Quadro 2. Plantas medicinais e princípios ativos com seus respectivos mecanismos de ação contra a acne.

\begin{tabular}{|c|c|c|c|}
\hline $\begin{array}{c}\text { PLANTA } \\
\text { MEDICINAL/ } \\
\text { PRINCÍPIO ATIVO }\end{array}$ & ATIVIDADE & MECANISMO DE AÇÃO & REFERÊNCIA \\
\hline $\begin{array}{l}\text { Epigalocatequina-3- } \\
\text { galato (EGCG) }\end{array}$ & Reduz a lipogênese em sebócitos & $\begin{array}{l}\text { Ativa a via de sinalização AMPK (proteína } \\
\text { cinase ativada por AMP) que inibe a atividade } \\
\text { de SREBP (proteínas de ligação ao elemento } \\
\text { regulador de esterol) }\end{array}$ & Yoon et al. (2013) \\
\hline EGCG & Redução da produção sebácea & Inibe a 5 alfa redutase & $\begin{array}{l}\text { Mahmood et al. } \\
\text { (2013) }\end{array}$ \\
\hline EGCG & Redução da produção sebácea & Inibe a izoenzima 1 da 5 alfa redutase & Liao (2001) \\
\hline EGCG & Redução da produção sebácea & Inibe a izoenzima 1 da 5 alfa redutase & $\begin{array}{l}\text { Mahmood et al. } \\
\qquad(2010)\end{array}$ \\
\hline $\begin{array}{l}\text { Extrato de folhas } \\
\text { Orthosiphon stamineu }\end{array}$ & Redução da produção sebácea & $\begin{array}{c}\text { Reduz a expressão de RNAm da } 5 \text { alfa } \\
\text { redutase do tipo } 1\end{array}$ & $\begin{array}{l}\text { Vogelgesang et al. } \\
\text { (2011) }\end{array}$ \\
\hline EGCG & Redução da produção sebácea & Inibidores naturais da mTORC1 & $\begin{array}{l}\text { Melnik e Schmitz } \\
\text { (2013) }\end{array}$ \\
\hline EGCG & $\begin{array}{l}\text { Ação anti-inflamatória, redução dos } \\
\text { níveis de mRNA de IL-1 } \alpha \text {, IL-1 } 1 \beta \text {, IL-8 } \\
\text { e TNF- } \alpha \text { em sebócitos SEB-1 induzida } \\
\text { por } C \text {. acnes }\end{array}$ & Inibição das vias NF- $\kappa$ B e AP-1 & Yoon et al. (2013) \\
\hline EGCG & Ação antinflamatória & Não especificou mecanismo & $\begin{array}{l}\text { Mahmood et al. } \\
\text { (2013) }\end{array}$ \\
\hline $\begin{array}{l}\text { Extratos dos grãos de } \\
\text { frutos crus de Mangifera } \\
\text { indica }\end{array}$ & $\begin{array}{l}\text { Ação antinflamatória, efeito inibitório } \\
\text { siginificativo sobre a secreção de IL-8. }\end{array}$ & Não especificou mecanismo & $\begin{array}{l}\text { Poomanee et al. } \\
\qquad(2018)\end{array}$ \\
\hline Extratos de Aloe ferox & $\begin{array}{c}\text { Ação antinflamatória, redução das } \\
\text { citocinas pró-inflamatórias TNF- } \alpha \text {, IL- } \\
1 \beta, \text { IL-6 e IL-8 }\end{array}$ & $\begin{array}{l}\text { Aloína e aloe-emodina têm efeitos } \\
\text { antiinflamatórios inibindo iNOS e COX-2 }\end{array}$ & $\begin{array}{l}\text { Jeong e Kim } \\
\quad(2017)\end{array}$ \\
\hline $\begin{array}{l}\text { Extrato da raiz de } \\
\text { Scutellariae radix }\end{array}$ & $\begin{array}{c}\text { Ação antiinflamatória, apresentou } \\
\text { inibição das interleucinas IL-8, IL-1 } \beta \text {, } \\
\text { IL-6 e do TNF- } \alpha\end{array}$ & Não especificou mecanismo & Tsai et al. (2016) \\
\hline $\begin{array}{l}\text { Extrato etanólico das } \\
\text { folhas de Orthosiphon } \\
\text { stamineus }\end{array}$ & $\begin{array}{c}\text { Ação anti-inflamatória, regulação } \\
\text { negativa do TNF- } \alpha\end{array}$ & Não especificou mecanismo & Choo et al. (2018) \\
\hline $\begin{array}{l}\text { Extrato dos grãos de } \\
\text { frutos crus de Mangifera } \\
\text { indica }\end{array}$ & Atividade antibacteriana & $\begin{array}{l}\text { Alto teor de compostos polifenólicos que } \\
\text { promovem danos à membrana celular do } C \text {. } \\
\text { acnes com consequente liberação de } \\
\text { substâncias citoplasmáticas }\end{array}$ & $\begin{array}{l}\text { Poomanee et al. } \\
\qquad(2018)\end{array}$ \\
\hline EGCG & Atividade antibacteriana & $\begin{array}{l}\text { Interações moleculares entre trifenóis de } \\
\text { EGCG e estrutura peptídica de proteínas } \\
\text { bacterianas incluindo os peptideosglicanos }\end{array}$ & Yoon et al. (2013) \\
\hline Estrictinina (derivada do & Atividade antibacteriana & Não especificou mecanismo & Hsieh et al. (2016) \\
\hline
\end{tabular}


Research, Society and Development, v. 10, n. 2, e12810212153, 2021

(CC BY 4.0) | ISSN 2525-3409 | DOI: http://dx.doi.org/10.33448/rsd-v10i2.12153

\begin{tabular}{|c|c|c|c|}
\hline chá verde) & Atividade antibacteriana & Não especificou mecanismo & Vora et al. (2018) \\
\hline $\begin{array}{c}\text { Extrato de Rosmarinus } \\
\text { officinalis }\end{array}$ & Atividade antibacteriana & Não especificou mecanismo & Hou et al. (2019) \\
\hline $\begin{array}{c}\text { Oleo essencial da casca } \\
\text { de Citrus reticulata } \\
\text { Blanco }\end{array}$ & Atividade antibacteriana & Não especificou mecanismo & Jeong e Kim \\
\hline $\begin{array}{c}\text { Extrato de Aloe ferox } \\
(2017) .\end{array}$ \\
\hline $\begin{array}{c}\text { Extrato de Myrtus } \\
\text { communis }\end{array}$ & Atividade antibacteriana & $\begin{array}{c}\text { Aumento da sensibilidade das células } \\
\text { bacterianas ao sistema imunológico; } \\
\text { Perda da virulência das células bacterianas }\end{array}$ & $\begin{array}{c}\text { Pecastaings et al. } \\
(2018)\end{array}$ \\
\hline
\end{tabular}

Fonte: Autores (2021).

Observa-se na maioria dos trabalhos que os polifenóis e seus compostos ativos estão envolvidos na atividade anti acne, o que pode ser justificado por sua já descrita atividade antinflamatória, sebossupressora e antimicrobiana. Autores que avaliaram o mesmo polifenol apresentaram consenso acerca das atividades que este apresentou, entretanto, as vias pelas quais eles atuam divergiram entre os resultados dos autores. Da mesma forma a capacidade antinflamatória foi investigada em diversos estudos acerca dos polifenóis, sugerindo em alguns estudos a via de sinalização pela qual estes compostos agem. Nos estudos os autores avaliaram diferentes plantas medicinais, e propuseram esta capacidade por diferentes compostos em vias de sinalização distintas, como pela inibição das vias NF-אB e AP-1 e pela inibição da óxido nítrico sintase induzível (iNOS) e ciclooxigenase - 2 (COX-2). Kim, Lee e Lee (2014) mencionam em seu estudo a ação antinflamatória dos polifenóis já descrita por estas vias de sinalização, além de citar que há outras vias também pelas quais os compostos polifenólicos atuam, como pela via do ácido araquidônico que envolve a Fosfolipase A, Ciclooxigenase e Lipoxigenase, além de outros fatores de transcrição como STAT-1. Estes achados corroboram com os descritos por Tuñón, García-Mediavilla, Sánchez-Campos e GonzálezGallego (2009) e González-Gallego, García-Mediavilla, Sánchez-Campos e Tunón, (2010) que atribuíram aos polifenóis a capacidade de agir sobre alguns fatores de transcrição como o NF-КB, AP-1, STAT-1, além de modular a expressão de marcados pró-inflamatórios como COX-2, iNOS, TNF- $\alpha$, IL-1 $\beta$ e IL-6.

De acordo com Tuñón et al. (2009) e Marzocchella et al. (2011) os flavonoides que pertencem a classe dos compostos polifenólicos, apresentam a capacidade de modular o metabolismo do ácido araquidônico que por sua vez inibe a atividade da fosfoslipase A e inibe a expressão da proteína COX. A redução dessas moléculas reduz a concentração de leucotrienos e prostanoídes, sugerindo este mecanismo assim como Kim et al. (2014), pelo qual os polifenóis apresentam atividade antiinflamatória. O mecanismo de inibição da fosfolipase A por flavonoides também é apoiado segundo Rathee et al. (2009), uma vez que já foram descritas em diversos estudos in vitro e in vivo.

Com o exposto evidencia-se a capacidade antinflamatória de polifenóis que são compostos presentes em grande parte das plantas medicinais, entretanto é viável o maior esclarecimento acerca das moléculas com esta capacidade e as respectivas vias de sinalização pelas quais atuam. Com os resultados das pesquisas avaliadas, observa-se a variedade de compostos bioativos nas plantas medicinais. Como exposto, a atividade antibacteriana do extrato de A. ferox foi sugerida por Jeong e Kim (2017) como resultado da atuação dos compostos aloemodina, crisopanol e aloína presentes no extrato. Entretanto Chen, Wyk, Vermaak e Viljoen (2012) descrevem que o gênero Aloe é utilizado também como agente antinflamatório e na cicatrização. Para tanto a investigação dos compostos bioativos envolvidos nestas atividades devem ser avaliados, levando em consideração os que já foram correlacionados com a atividade antibacteriana desta planta.

As plantas medicinais não são utilizadas em escalas proporcionais para infecções microbianas, quando comparadas aos medicamentos convencionais. A possível resistência microbiana das plantas medicinais ainda não está clara, entretanto 
estudos in vitro realizados acerca deste tópico sugerem uma improbabilidade deste fato ocorrer. Este fato é apoiado considerando que as plantas medicinais com capacidade antimicrobiana exibem esta função em amplo espetro sendo antiviral, antifúgicas e antiprotozoários simultaneamente, estimulando as defesas imunológicas do hospedeiro (Enioutina et al., 2017).

As atividades advindas de plantas medicinais se mostram confiáveis e podem ser consideradas fontes promissoras para o desenvolvimento de novos tratamentos que utilizem da medicina alternativa (Nasri et al., 2015). Para tanto é necessário avaliar as ações dos compostos ativos presentes nas plantas medicinais correlacionando aos seus respectivos efeitos terapêuticos, sendo assim possível inferir o direcionamento das mesmas em condições clínicas especificas como na acne.

\section{Considerações Finais}

A terapia para a acne inflamatória é desafiadora, uma vez que há efeitos colaterais e a resistência bacteriana frente às terapias preconizadas na atualidade. Essas limitações presentes nas terapias utilizadas no tratamento da acne, exigem a necessidade do desenvolvimento de novos medicamentos anti acne eficazes, com menos efeitos colaterais e que diminuam a resistência bacteriana aos medicamentos. As evidências dos efeitos benéficos na acne por intermédio de plantas medicinais já são bem estabelecidas, sugerindo que extratos vegetais e fitoquímicos apresentam capacidade promissora na terapia na acne, podendo sanar os desafios aturais nesse âmbito. Os derivados de plantas medicinais apresentam uma abordagem sustentável que conduz à nova tendência explorada pela indústria.

\section{Referências}

Almela, L., Sánchez-Muñoz, B., Fernández-López, J. A., Roca, M. J., \& Rabe, V. (2006). Liquid chromatograpic-mass spectrometric analysis of phenolics and free radical scavenging activity of rosemary extract from different raw material. Journal of Chromatography A, 1120, 221-229. 10.1016 / j.chroma.2006.02.05

Bhambri, S., Rosso, J. Q. D., \& Bhambri, A. (2009). Pathogenesis of acne vulgaris: recent advances. Journal of Drugs in Dermatology, 8(7), 615-618.

Brasil. (2015). Ministério da Saúde, Secretaria de Atenção à Saúde. Portaria nº. 1159, de 18 de novembro de 2015. Brasília.

Buffon, M. C. M., Lima, M. L. C., Galarda, I., \& Cogo, L. (2001). Avaliação da eficácia dos extratos de Malva sylvestris, Calendula officinalis, Plantago major e Curcuma zedoarea no controle do crescimento das bactérias da placa dentária. Estudo "in vitro". Revista Visão Acadêmica, 2(1). 31-38.

Canavan, T. N., Chen, E., \& Elewski, B. E. (2016). Optimizing Non-Antibiotic Treatments for Patients with Acne: A Review. Dermatologic Therapy (Heidelb), 6(4), 555-578. 10.1007 / s13555-016-0138-1

Carson, C. F., Mee, B. J., \& Riley, T. V. (2002). Mechanism of action of Melaleuca alternifolia (tea tree) oil on Staphylococcus aureus determined by timekill, lysis, leakage, and salt tolerance assays and electron microscopy. Antimicrobial Agents and Chemotherapy, 46(6), 1914-1920. 10.1128 / aac.46.6.19141920.2002

Castillo, D. E., Nanda, S., \& Keri, J. E. (2019). Propionibacterium (Cutibacterium) acnes Bacteriophage Therapy in Acne: Current Evidence and Future Perspectives. Dermatologia e Terapia, 9(1), 19-31. 10.1007 / s13555-018-0275-9

Chahal, D. S., Sivamani, R. K., Isseroff, R. R., \& Dasu, M. R. (2013). Plant-Based Modulation of Toll-like Receptors: An Emerging Therapeutic Model. Phytotherapy Research, 27(10), 1423-1438. https://doi.org/10.1002/ptr.4886

Chen, W., Wyk, Ben-Erik. V., Vermaak, I., \& Viljoen, A. M. (2012). Cape aloes - A review of the phytochemistry, pharmacology and commercialisation of Aloe ferox. Phytochemistry Letters, 5(1), 1-12. 10.1016 / j.phytol.2011.09.001

Choo, B. K. M., Kundap, U. P., Kumari, Y., Hue, S. M., Othman, I., \& Shaikh, M. F. (2018). Orthosiphon stamineus Leaf Extract Affects TNF- $\alpha$ and Seizures in a Zebrafish Model. Frontiers in Pharmacology, 9, 1-11. https://doi.org/10.3389/fphar.2018.00139

Daglia, M. (2012). Polyphenols as antimicrobial agents. Current Opinion in Biotechnology, 23(2), 174-181. https://doi.org/10.1016/j.copbio.2011.08.007

Dessinioti, C., \& Katsambas, A. D. (2010). The role of Propionibacterium acnes in acne pathogenesis: facts and controversies. Clinics In Dermatology, 28(1), 2-7. $10.1016 /$ j.clindermatol.2009.03.012

Dhillon, KS., \& Varshney, K. R. (2013). Study of Microbiological Spectrum in Acne Vulgaris: An In Vitro Study. Scholars Journal of Applied Medical Sciences, 1(6), 724-727.

Dreno, B., Gollnick, H. P. M., Kang, S., Thiboutot, D., Bettoli, V.,Torres, V., \& Leyden, J. (2015). Understanding innate immunity and inflammation in acne: implications for management. Journal Of The European Academy Of Dermatology And Venereology, 29(Suppl 4), 3-11. 10.1111 / jdv.13190 
Dreno, B., Poli, F., Pawin, H., Beylot, C., Faure, M., Chivot, M., Auffret, N., Moyse, D., Ballanger, F., \& Revuz, J. (2011). Development and evaluation of a Global Acne Severity Scale (GEA Scale) suitable for France and Europe. Journal of the European Academy of Dermatology and Venereology, 25(1), 43-48. $10.1111 /$ j.1468-3083.2010.03685.x

Enioutina, E. Y., Teng, L., Fateeva, T. V., Brown, J. CS., Job, K. M., Bortnikova, V. V., Krepkova, L. V., Gubarev, M. I., \& Sherwin, C. MT. (2017). Phytotherapy as an alternative to conventional antimicrobials: combating microbial resistance. Expert Review of Clinical Pharmacology, $10(11), 1203-1214$. $10.1080 / 17512433.2017 .1371591$

Eumkeba, G., Sakdarat, S., \& Siriwonga, S. (2010). Reversing $\beta$-lactam antibiotic resistance of Staphylococcus aureus with galangin from Alpinia officinarum Hance and synergism with ceftazidime. Phytomedicine, 18 (1), 40-45. 10.1016 / j.phymed.2010.09.003

Feldman, S. R., Tan, J., Poulin, Y., Dirschka, T., Kerrouche, N., \& Manna, V. (2011). The efficacy of adapalene-benzoyl peroxide combination increases with number of acne lesions. Journal of the American Academy of Dermatology, 64(6), 1085-1091. 10.1016/ j.jaad.2010.03.036

Fisk, W. A., Lev-Tov, H. A., \& Sivamani, R. K. (2014). Botanical and Phytochemical Therapy of Acne: A Systematic Review. Phytotherapy Research, 28(8), 1137-1152. $10.1002 /$ ptr.5125

Food and drug administration. (2018). Contains Nonbinding Recommendations: Draft Guidance on Adapalene; Benzoyl peroxide. Recuperado 2020, de https://www.accessdata.fda.gov/drugsatfda_docs/psg/Adapalene_Benzoyl_Peroxide_Gel_NDA_207917_RV_Nov_2018.pdf.

Fox, L., Csongradi, C., Aucamp, M., Plessis, J. D.,\& Gerber, M. (2016). Treatment Modalities for Acne. Molecules, 21(8), 1-20. 10.3390 / moléculas21081063

González-Gallego, J., García-Mediavilla, M. V., Sánchez-Campos, S., \& Tuñón, M. J. (2010). Fruit polyphenols, immunity and inflammation. British Journal of Nutrition, 104, S15-27.

Grice, E. A., Kong, H. H., Conlan, S., Deming, C. B., Davis, J., Young, A. C., Bouffard, G. G., Blakesley, R. W., Murray, P. R., Green, E. D., Turner, M. L., \& Segre, J. A. (2009). Topographical and temporal diversity of the human skin microbiome. Science, 324(5931), 1190-1192. 10.1126/ science.1171700

Han, R., Blencke, H. M., Cheng, H., \& Li, C. (2018). The antimicrobial effect of CEN1HC-Br against Propionibacterium acnes and its therapeutic and antiinflammatory effects on acne vulgaris. Peptides, 99, 36-43. 10.1016/ j.peptides.2017.11.001

Hou, H. S., Bonku, E. M., Zhai, R., Zeng, R., Hou, Y. L., Yang, Z. H., \& Quan, C. (2019). Extraction of essential oil from Citrus reticulate Blanco peel and its antibacterial activity against Cutibacterium acnes (formerly Propionibacterium acnes). Heliyon, 5(12), e02947. https://doi.org/10.1016/j.heliyon.2019.e02947

Hsieh, S. K., Xu, J. R., Lin, N. H., Li, Y. C., Chen, G. H., Kuo, P. C., Chen, W. Y., \& Tzen, J. TC. (2016). Antibacterial and laxative activities of strictinin isolated from Pu'er tea (Camellia sinensis). Journal of Food and Drug Analysis, 24(4), 722-729.

Issabeagloo, E., Kermanizadeh, P., Taghizadieh, M., \& Forughi, R. (2012). Antimicrobial effects of rosemary (Rosmarinus officinalis L.) essential oils against Staphylococcus spp. African Journal of Microbiology Research, 6(23), 5039-5042. https://doi.org/10.5897/AJMR12.741

Jasson, F., Nagy, I., Knol, A. C., Zuliani, T., Khammari, A., \& Dréno, B. (2013). Different strains of Propionibacterium acnes modulate differently the cutaneous innate immunity. Experimental Dermatology, 22(9), 587-592. 10.1111/ exd.12206

Jeong, W. Y., \& Kim, K. (2017). Anti-Propionibacterium acnes and the Anti-Inflammatory Effect of Aloe ferox Miller Components. Journal of Herbal Medicine, 9, 53-59. https://doi.org/10.1016/j.hermed.2017.03.009

Kim, J. (2005). Review of the Innate Immune Response in Acne vulgaris: Activation of Toll-Like Receptor 2 in Acne Triggers Inflammatory Cytokine Responses. Dermatology, 211(3), 193-198. 10.1159/000087011

Kim, J., Lee, K. W., \& Lee, H. J. (2014). Polyphenols Suppress and Modulate Inflammation: Possible Roles in Health and Disease. Polyphenols in Human Health and Disease, 1, 393-408. 10.1016 / B978-0-12-398456-2.00029-3

Kim, J., Ochoa, M., Krutzik, S. R., Takeuchi, O., Uematsu, S., Legaspi, A. J., Brightbill, H. D., Holland, D., Cunliffe, W. J., Akira, S., Sieling, P. A., Godowski , P. J., \& Modlin, R. L. (2002). Activation of Toll-Like Receptor 2 in Acne Triggers Inflammatory Cytokine Responses. The Journal of Immunology, 169(3), 1535-1541. 10.4049/ jimmunol.169.3.1535

Kim, S. Y., \& Ochsendorf, F. R. (2016). New Developments in Acne Treatment: Role of Combination Adapalene-Benzoylperoxide. Therapeutics and Clinical Risk Managemen, 12, 1497-1506. https://doi.org/10.2147/TCRM.S94062

Kistowska, M., Gehrke, S., Jankovic, D., Kerl, K., Fettelschoss, A., Feldmeyer, 1., Fenini, G., Kolios, A., Navarini, A., Ganceviciene, R., Schauber, J., Contassot, E., \& Francês, L. E. (2014). IL-1 $\beta$ drives inflammatory responses to Propionibacterium acnes in vitro and in vivo. Journal of Investigative Dermatology, 134(3), 677-685. 10.1038/jid.2013.438

Lamarão, R. C., \& Fialho, E. (2009). Functional aspects of green tea catechins in the cellular metabolism and their relationship with body fat reduction. Revista de Nutrição, 22(2), 257-269. 10.1590/S1415-52732009000200008

Leal, C. A. E., \& Lara, S. G. (2019). Current Methods for the Discovery of New Active Ingredients from Natural Products for Cosmeceutical Applications. Planta médica, 85(7), 535-551. 10.1055 / a-0857-6633

Lee, Y. B., Byun, E. J., \& Kim, H. S. (2019). Potential Role of the Microbiome in Acne: A Comprehensive Review. Journal of Clinical Medicine, 8(7), 1-25. $10.3390 /$ jcm8070987

Leyden, J. J. (2003). A review of the use of combination therapies for the treatment of acne vulgaris. Journal of the American Academy of Dermatology, 49(Suppl 3), 200-210. 10.1067 / s0190-9622 (03) 01154-x

Leyden, J. J. (2012). In vivo antibacterial effects of tretinoin-clindamycin and clindamycin alone on Propionibacterium acnes with varying clindamycin minimum inhibitory. Journal of Drugs in Dermatology, 11(12), 1434-1438. 
Li, Z., Summanen, P. H., Downes, J., Corbett, K., Komoriya, T., Henning, S. M., Kim, J., \& Finegold, S. M. (2015). Antimicrobial Activity of Pomegranate and Green Tea Extract on Propionibacterium acnes, Propionibacterium granulosum, Staphylococcus aureus and Staphylococcus epidermidis. Journal of Drugs in Dermatology, 14(6), 574-578.

Liao, S. (2001). The medicinal action of androgens and green tea epigallocatechin gallate. Hong Kong Medical Journal, 7(4), 369-374.

Lomholt, H. B., \& Kilian, M. (2010). Population Genetic Analysis of Propionibacterium acnes Identifies a Subpopulation and Epidemic Clones Associated With Acne. PLoS One, 5(8), e12277. 10.1371/ journal.pone.0012277

Maeda-Yamamoto, M., Nagai, H., Asai, K., Tachibana, H., Miyase, T., San, M., Moriwaki, S., Horie, H., \& Kohata, K. (2004). Changes in Epigallocatechin3-O-(3-O-methyl) Gallate and Strictinin Contents of Tea (Camellia sinensis L.) Cultivar 'Benifuki' in Various Degrees of Maturity and Leaf Order. Food Science and Technology Research, 10(2), 186-190.

Mahmood, T., Akhtar, N., \& Moldavo, C. (2013). A comparison of the effects of topical green tea and lotus on facial sebum control in healthy humans. Hippokratia, 17(1), 64-67.

Mahmood, T., Akhtar, N., Khan, B. A., Khan, H. M. S., \& Saeed, T. (2010). Outcomes of $3 \%$ green tea emulsion on skin sebum production in male volunteers. Bosnian Journal Of Basic Medical Sciences, 10(3), 260-264. 10.17305 / bjbms.2010.2697

Mansu, S. S. Y., Coyle, M., Wang, K., May, B., Zhang, A. L., \& Xue, C. C. L. (2018). Herbal medicine Eriobotrya japonica formula for acne vulgaris: A systematic review. Journal of Herbal Medicine, 11, 12-23. https://doi.org/10.1016/j.hermed.2017.09.001

Marzocchella, L., Fantini, M., Benvenuto, M., Masuelli, L., Tresoldi, I., Modesti, A., \& Bei, R. (2011). Dietary flavonoids: molecular mechanisms of action as anti- inflammatory agents. Recent Patents on Inflammation \& Allergy Drug Discovery, 5(3), 200-220. 10.2174 / 187221311797264937

Matsuchita, H. L. P., \& Matsuchita, A. S. P. (2014). Uso da Própolis na Prevenção e Tratamento da Acne Vulgar. Uniciências, 18(1), $19-23$.

Mcinturff, J. E., \& Kim, J. (2005). The Role of Toll-Like Receptors in the Pathophysiology of Acne. Seminars in Cutaneous Medicine and Surgery, 24(2), 7378. $10.1016 /$ j.sder.2005.03.002.

Mcinturff, J. E., Modlin, R. L., \& Kim, J. (2005). The Role of Toll-like Receptors in the Pathogenesis and Treatment of Dermatological Disease. The Journal of Investigative Dermatology, 125(1), 1-8. 10.1111/ j.0022-202X.2004.23459.x

Melnik, B. C. (2015). Linking diet to acne metabolomics, inflammation, and comedogenesis: an update. Clinical, Cosmetic and Investigational Dermatology, 8, 71-388. 10.2147 / CCID.S69135

Melnik, B. C., \& Schmitz, G. (2013). Are therapeutic effects of antiacne agents mediated by activation of FoxO1 and inhibition of mTORC1?. Experimental Dermatology, 22, 502-504.

Melnik, B. C., \& Zouboulis, C. C. (2013). Potential role of FoxO1 and mTORC1 in the pathogenesis of Western diet-induced acne. Experimental Dermatology, 22, 311-315. https://doi.org/10.1111/exd.12172

Melnik, C. B. (2018). Acne vulgaris: The metabolic syndrome of the pilosebaceous follicle. Clinics In Dermatology, 36(1), 29-40. 10.1016 / j.clindermatol.2017.09.006

Michael, C. A., Dominey-Howes, D., \& Maurizio, L. (2014). The Antimicrobial Resistance Crisis: Causes, Consequences, and Management. Frontiers in Public Health, 2, 1-8. https://doi.org/10.3389/fpubh.2014.00145

Montagner, S., \& Costa, A. (2010). Diretrizes modernas no tratamento da acne vulgar: da abordagem inicial à manutenção dos benefícios clínicos. Surgical \& Cosmetic Dermatology, 2(3), 205-213.

Mukherjeea, P. K., Maity, N., Nema, N. K., \& Sarkar, B. K. (2011). Bioactive compounds from natural resources against skin aging. Phytomedicine, 19(1), 64-73. 10.1016/ j.phymed.2011.10.003

Nasri, H., Bahmani, M., Shahinfard, N., Nafchi, A. M., Saberianpour, S., \& Kopaei, M. R. (2015). Medicinal Plants for the Treatment of Acne Vulgaris: A Review of Recent Evidences. Jundishapur Journal of Microbiology, 8(11), e25580. 10.5812 / jjm.25580

Nichols, J. A., \& Katiyar, S. K. (2010). Skin photoprotection by natural polyphenols: anti-inflammatory, antioxidant and DNA repair mechanisms. Archives of Dermatology, 302(2), 71- 83. 10.1007 / s00403-009-1001-3

O'neill A. M., \& Gallo, R. L. (2018). Host-microbiome interactions and recent progress into understanding the biology of acne vulgaris. Microbiome, 6(1), 177. $10.1186 / \mathrm{s} 40168-018-0558-5$

Pathak, R., Kasama, N., Kumar, R., \& Gautam, H. K. (2013). Staphylococcus epidermidis in Human Skin Microbiome associated with Acne: A Cause of Disease or Defence? Research Journal Of Biotechnology, 8(12), 78-82.

Pecastaings, S., Roque, C., Nocera, P. C., Mengeaud, V., Khammari, A., \& Dréno, B. (2018). Characterisation of Cutibacterium acnes phylotypes in acne and in vivo exploratory evaluation of Myrtacine. Journal of the European Academy of Dermatology and Venereology, 32(Suppl 2), 15-23. 10.1111 / jdv.15042

Poomanee, W., Chaiyana, W., Mueller, M., Viernstein, H., Khunkitti, W., \& Leelapornpisid, P. (2018). In-vitro investigation of anti-acne properties of Mangifera indica L. kernel extract and its mechanism of action against Propionibacterium acnes. Anaerobe, 52, 64-74. 10.1016/ j.anaerobe.2018.05.004

Porstmann, T., Santos, C.R., Lewis, C., Griffiths, B., \& Schulze, A. (2009). A New Player in the Orchestra of Cell Growth: SREBP Activity Is Regulated by mTORC1 and Contributes to the Regulation of Cell and Organ Size. Biochemical Society Transactions, 37, 78-283. 10.1042 / BST0370278 
Quinn, W. J., \& Birnbaum, M. J. (2012). Distinct mTORC1 pathways for transcription and cleavage of SREBP-1c. Proceedings of the National Academy of Sciences of the United States America, 109(40), 15974-15975. https://doi.org/10.1073/pnas.1214113109

Ramli, R., Malik, A. S., Hani, A. F. M., \& Jamil, A. (2012). Acne analysis, grading and computational assessment methods: an overview. Skin Research and Technology, 18(1), 1-14. 10.1111/j.1600-0846.2011.00542.x

Rathee, P., Chaudhary, H., Rathee, S., Rathee, D., Kumar, V., \& Kohli, K. (2009). Mechanism of action of flavonoids as anti-inflammatory agents: a review. Inflammation \& Allergy - Drug Targets, 8(3), 229-235. 10.2174 / 187152809788681029

Ruiz, A. C. A., Hernández, O.M., Torres-Tobar, L., Garzón, M. G., Reverend, C., Ayala, C. A., Rueda, J. C., \& Díaz, A. T. (2019). Caracterización de las cepas de Cutibacterium acnes en pacientes con diagnóstico de acné en una población colombiana. Piel: Formación continuada en dermatología, 34(4), 204211.

Sadhasivam, S., Sinha, M., Saini, S., Kaur, S. P., Gupta, T., Sengupta, S., Ghosh, S., \& Sardana, K. (2016). Heterogeneity and antibiotic resistance in Propionibacterium acnes isolates and its therapeutic implications: blurring the lines between commensal and pathogenic phylotypes. Dermatologic Therapy, 29(6), 451-454. https://doi.org/10.1111/dth.12391

Saewan, N., \& Jimtaisong, A. (2015). Natural products as photoprotection. Journal of Cosmetic Dermatology, 14(1), 47-63. https://doi.org/10.1111/jocd.12123 Saha, R. (2012). Cosmeceuticals and herbal drugs: practical uses. International Journal of Pharmaceutical Sciences and Research, 3(1), 59-65.

Sand, F. L., \& Thomsen, S. F. (2013). Adalimumab for the Treatment of Refractory Acne Conglobata. JAMA Dermatology, 149(11), 1306-1307. 10.1001 / jamadermatol.2013.6678

Silva, A. F., Costa, F.P., \& Moreira, M. (2014). Acne vulgar: diagnóstico e manejo pelo médico de família e comunidade. Revista Brasileira de medicina de família e comunidade, 9(30), 54-63. https://doi.org/10.5712/rbmfc9(30)754

Silva, A. M. O., Andrade-Wartha, E. R. S., Carvalho, E. B. T., Lima, A., Novoa, A. V., \& Filho-Mancini, J. (2011). Effect of aqueous rosemary extract (Rosmarinus officinalis L.) on the oxidative stress of diabetic rats. Revista de Nutrição, 24(1), 121-130.

Thiboutot, D. (2011). Dermatologists Do Not Yet Fully Understand the Clinical Significance of Antibiotic Use and Bacterial Resistance in Patients With Acne. Archives of Dermatology, 147(8), 921-922. 10.1001/archdermatol.2011.201

Thiboutot, D., Gollnick, H., Vincenzo, B., Dréno, B., Kang, S., Leyden, J. J., Shalita, A. R., Lozada, V. T., Berson, D., Finlay, A., Goh, C. L., Herane, M. I., Kaminsky, A., Kubba, R., Layton, A., Miyachi, Y., Perez, M., Martin, J. P., Silva, M. R., See, J. A., Shear, N., \& Jr, J. W. (2009). New insights into the management of acne: An update from the Global Alliance to Improve Outcomes in Acne Group. Journal of the American Academy of Dermatology, 60(Suppl 5), 1-50. 10.1016/ j.jaad.2009.01.019

Totté, JEE., Feltz, WT, V., Bode, LGM., Belkum, A. V., Zuuren, EJ. V., \& Pasmans, SGMA. (2016). A systematic review and meta-analysis on Staphylococcus aureus carriage in psoriasis, acne and rosacea. European Journal of Clinical Microbiology \& Infectious Diseases, 35(7), 1069-1077. 10.1007 / s10096-016-2647-3

Tsai, P, J., Huang, W. C., Hsieh, M. C., Sung, P. J., Kuo, Y. H., \& Wu, W. H. (2016). Flavones Isolated from Scutellariae radix Suppress Propionibacterium Acnes - Induced Cytokine Production In Vitro and In Vivo. Molecules, 21(1), 1-11. 10.3390 / moléculas21010015

Tuñón, MJ., García-Mediavilla, MV., Sánchez-Campos, S., \& González-Gallego, J. (2009). Potential of flavonoids as anti-inflammatory agents: modulation of pro-inflammatory gene expression and signal transduction pathways. Current Drug Metabolism, 3, $256-271$.

Upadhyay, A., Upadhyaya, I., Kollanoor-Johny, A., \& Venkitanarayanan, K. (2014). Combating Pathogenic Microorganisms Using Plant-Derived Antimicrobials: A Minireview of the Mechanistic Basis. BioMed Research International, 2014, 1-18. https://doi.org/10.1155/2014/761741

Vogelgesang, B., Malak, N. A., Reymermier., Altobelli, C., \& Saget, J. (2011). On the effects of a plant extract of Orthosiphon stamineus on sebum-related skin imperfections. International Journal of Cosmetic Science, 33(1), 44-52. 10.1111/ j.1468-2494.2010.00581.x

Vora, J., Srivastava, A., \& Modi, H. (2018). Antibacterial and antioxidant strategies for acne treatment through plant extracts. Informatics in Medicine Unlocked, 13, 128-132. https://doi.org/10.1016/j.imu.2017.10.005

Williams, H. C., Dellavalle, R. P., \& Garner, S. (2012). Acne vulgaris. Lanceta, 379(9813), 361-372. 10.1016/ S0140-6736 (11) 60321-8

Wolff, K., Johnson, R. A., Saavedra, A. P., \& Roh, E. K. (2019). Dermatologia de Fitzpatrick. Porto Alegre: (8 ed). AMGH.

Yam, M. F., Lim, V., Salman, I. M., Ameer, O. Z., Ang, L. F., Rosidah, N., Abdulkarim, M. F., Abdullah, G. Z., Basir, R., Sadikun, A., \& Asmawi, M. Z. (2010). HPLC and anti-inflammatory studies of the flavonoid rich chloroform extract fraction of Orthosiphon stamineus leaves. Molecules, 15(6), 4452-4466. 10.3390 / moléculas 15064452

Yoon, J. Y., Know, H. H., Min, S. U., Thiboutot, D. M., \& Suh, D. H. (2013). Epigallocatechin-3-Gallate Improves Acne in Humans by Modulating Intracellular Molecular Targets and Inhibiting P. acnes. Journal of Investigative Dermatology, 133(2), 429-440. 10.1038 / jid.2012.292

Zouboulis, CC., Jourdan, E., \& Picardo, M. (2014). Acne is an inflammatory disease and alterations of sebum composition initiate acne lesions. Journal of The European Academy of Dermatology And Venereology, 28(5), 527-532. 10.1111 / jdv.12298 